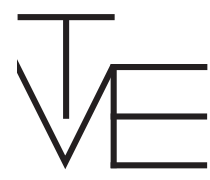

\title{
Efficient pricing of tourist sites
}

\author{
Ragnar Arnason ${ }^{1}$
}

\begin{abstract}
Foreign tourism has expanded very fast in Iceland in recent years. Much of this tourism targets relatively few places of particular natural beauty. This has resulted in two notable external effects; deterioration of some of the natural features of these sites and significant crowding in the more popular ones. These manifestations of scarcity suggest the social desirability of limiting access to these sites.

Basic economic theory holds that optimal use of scarce resources may be accomplished by means of prices. On that basis this paper considers prices for access to natural tourist sites. Optimal pricing rules are derived, their content explained and their practical applicability considered. Comparison of these optimal pricing rules to those that might be set by individual owners is briefly examined. While motivated by the Icelandic problem, the findings of the paper have general applicability.
\end{abstract}

JEL classification: Q21; Q26; D61.

Keywords: Tourist sites; limiting access; pricing of access; externalities; environmental costs.

1 The author is a professor at the Faculty of Economics, University of Iceland. E-mail: ragnara@hi.is. Useful suggestions from two anonymous referees on an earlier draft of this article are gratefully acknowledged. 


\section{Introduction}

There has been a great increase in foreign tourism in Iceland in recent years. According to official statistics (Ferðamálastofa 2017) about 1.3 million foreign visitors came to Iceland in 2015 and the corresponding number in 2016 was probably close to 1.8 million. Since 2010, the average annual rate of increase in the number of foreign visitors has been about $20 \%$. Even more strikingly, this rate of increase has been climbing, being just under 30\% in 2015 and probably close to $40 \%$ in 2016 . The evolution of the number of foreign visitors is illustrated in figure 1.

Foreign tourism in Iceland is heavily based on the country's extraordinary landscape (Geirsson and Jóhannesdóttir 2013, Jónsdóttir 2016). Most tourists that come to the country seek to visit one or more of its natural spectacles. As a result, the huge increase in the number of foreign tourists has led to a greatly increased pressure on many of the more popular tourist sites in Iceland. This has created two particularly notable economic externalities. First, many of these tourist sites have become overly crowded resulting in less enjoyable experience for the visitors. Second, the high number of visits to some tourist sites has had a detrimental impact on their natural quality. This applies especially to the living resources such as marine mammal, bird life and vegetation but also, in some cases, to delicate lava and other rock formations. While the living resources are generally renewable, albeit often at a slow rate, damage to rock formations is usually irreversible.

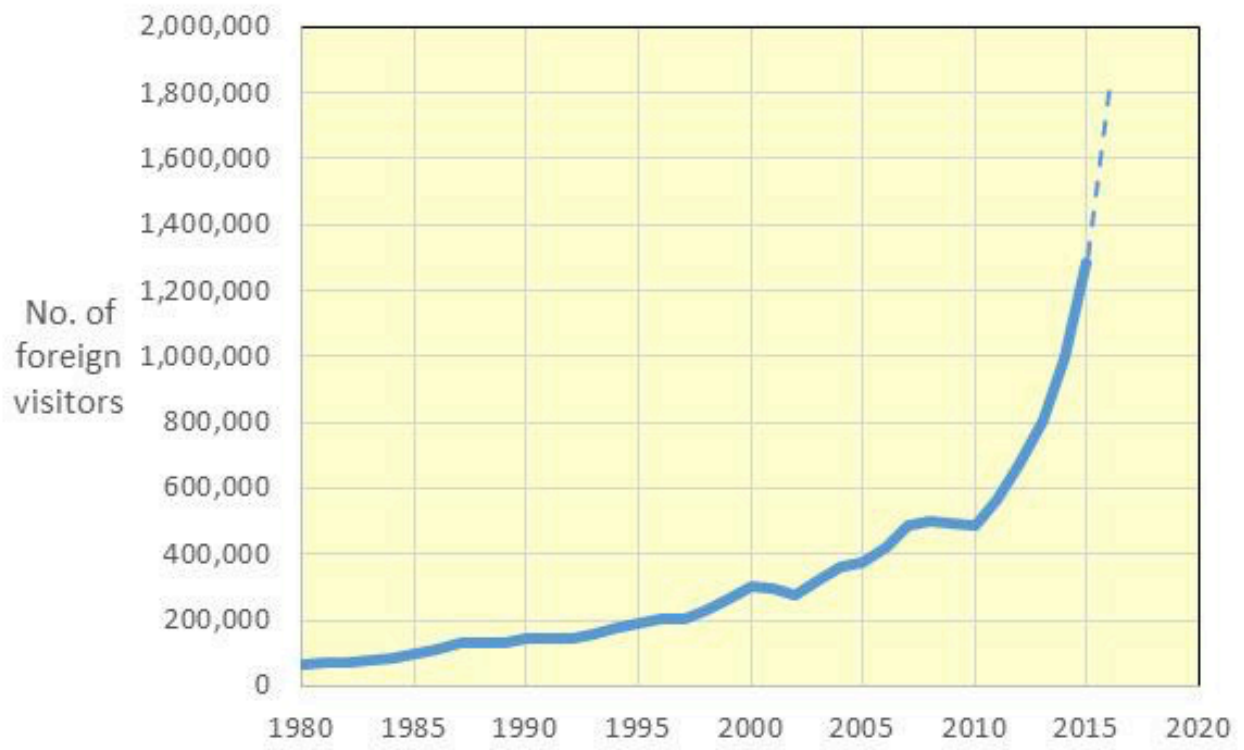

Figure 1. Number of foreign visitors 
These observations have made it clear that, far from being abundant, many of these tourist sites are in fact scarce resources and, therefore - at least if socially optimal use is desired - access to them needs to be restricted. It is well known that the optimal use of scarce resources may be attained with the help of the price system (see e.g. Arrow and Hahn 1971). The question of the optimal number of visitors to particular sites can therefore be seen as the question of the optimal pricing of access.

Until now, access to most of Iceland's natural tourist sites has been free of charge. In other words, an access price of zero generally applies. However, inter alia for the reasons outlined above, a great deal of public discussion about charging a positive price for access to natural sites in Iceland has arisen. A useful account of this debate and its main issues can be found in Jónsdóttir (2016). In recent years, some private owners of natural tourist sites have tried to impose an entrance fee to their sites (see e.g. Landeigendafélag Geysis 2015). For some reason, this has been resisted by the public authorities (see e.g. Viðskiptablaðið 2015).

In this paper we aim at deriving optimal pricing rules for access to natural tourist sites. For this purpose, we will investigate the pricing of access to tourist sites that maximizes the present value of the flow of benefits from these sites taking environmental damage and crowding at the sites as well as other relevant variables into account. Since most of these tourist spots are unique and, therefore, give rise to monopolistic pricing (Mill 1848, Varian 1987), we will also consider pricing rules that maximize the present value of profits from each tourist site. Due to the inherent complexity of the underlying situation, formal expressions for these pricing rules are inevitably somewhat involved. Their value, however, is that they highlight certain crucial components of optimal pricing and, thus, set the framework for the empirical work needed to actually implement optimal pricing principles in particular cases.

To keep the analysis reasonably simple, we will proceed in terms of one (representative) site. The extension to any number of sites is straightforward, but adds considerably to the complexity of the presentation without adding much to the fundamental pricing issue. It should be noticed, however, that to maximize total benefits over all possible tourist sites, the optimal pricing rules will have to reflect the ability of tourists to substitute one site for another.

Much of economic theory is concerned with the appropriate pricing of scarce resources. As a result, the literature on optimal pricing is enormous. A subset of this theory is concerned with optimal pricing in the presence of external effects such as crowding and environmental deterioration which are central to this paper. This branch of economics was initiated by the seminal work of Arthur Pigou in the early part of the 20th century (Pigou 1920) who suggested the imposition of the appropriate taxes and subsidies to induce 
agents to adapt optimally to the external effects. This price correction will be recognized as a variant of optimal pricing. Based on this groundwork, there has, since the 1970s, emerged a voluminous literature on market or pricebased corrections to deal with environmental externalities. Notable references for this are Spence and Weitzman (1978), Baumol and Oates (1988), Tietenberg (1990), Cropper and Oates (1992) and Hanley et al. (1997) among others.

Compared to many other environmental resources, papers dealing specifically with optimal pricing of access to natural tourist sites are relatively few and generally not particularly well-grounded in economic theory. Lindberg (1991) recognizes the natural and crowding constraints of nature-based tourism and how prices can assist in bringing the optimal utilization about, but does not derive optimal pricing rules. Clarke and Ng. (1993) explain that if the natural sites are owned by residents and are priced efficiently, the flow of social benefits from the sites are maximized and there is no need for special public charges or regulations. However, they do not derive optimal pricing rules. Laarman and Gregersen (1996) note that many natural parks and reserves charge access fees and wonder about the appropriate pricing principles. While they do not come up with any pricing formulae, they note that pricing can be a powerful tool to move toward greater efficiency and that, to date, this tool has been underutilized. Richter and Christensen (1999) also recognizing the impact of access prices stress that that pricing rules need to strike the balance between the need for fee revenues, interpersonal equity, the ability to pay as well as congestion. Thus, this paper as so many other papers about pricing of access to natural tourist does not argue from economic first principles, but takes the need to generate revenues and presumed social fairness and equity as constraints on pricing. None of these papers derives or even proposes optimal pricing rules. In fact, we have not been able to locate any previous work that specifically presents an explicit pricing rule for access to natural tourist sites.

The paper is organized as follows: In the next chapter the essence of the situation as described above will be modelled. Private behaviour, essentially individual demand for access, will be derived. Rules for the optimal number of visitors, i.e. the number that maximizes the flow of benefits from the tourist spots, will be stated. On this basis it will be shown that visits to most tourist spots will be excessive unless a positive price for access is charged. Formulae for the appropriate, i.e. the socially optimal, price will be presented. While the formula for the optimal price applies generally, the resulting access price would vary greatly across the different tourist spots. Pricing rules that maximize the present value of profits from selling access rather than social benefits will also be deduced and compared to the socially optimal ones. In chapter three, the practical implications and applications of the pricing rules will be discussed. 


\section{Modelling the situation}

We start by considering a typical tourist site. The natural features of this spot, animate and inanimate, may be represented by the vector $x$. Some elements of this vector such as animal life, vegetation, water resources and certain geological formations are renewable, albeit perhaps quite slowly in some cases. Others, such as lava and rock formations may not be renewable at all. We represent these renewal processes by the vector of renewal functions $G(x)$, where each element of this vector represents the renewal process for a particular natural feature. In the case of non-renewable elements of the natural features, the renewal function would be identically zero. For the renewable ones it would be positive for some values of the vector $x$. The entire natural evolution of the natural features may be described by the differential functions: $\dot{\boldsymbol{x}}=\boldsymbol{G}(\boldsymbol{x})$, where $\dot{\boldsymbol{x}}$ denotes the first derivative of the natural features with respect to time. An equilibrium of the natural features would simply be a solution to the equations $\boldsymbol{G}(\boldsymbol{x})=\mathbf{0}$.

Let us represent human impacts on the natural features of the tourist site by the vector $y$. Given this, the natural features of the tourist sites may be assumed to evolve as:

$$
\dot{\boldsymbol{x}}=\boldsymbol{G}(\boldsymbol{x})-\boldsymbol{y}^{3}
$$

And an equilibrium would be defined by $\boldsymbol{G}(\boldsymbol{x})-\boldsymbol{y}=\mathbf{0}$.

While (1) is a fairly general representation of the evolution of the natural features of a given tourist site, for simplicity of presentation, we will in what follows represent these natural features by a single variable and rewrite (1) as:

$$
\dot{x}=G(x)-y
$$

Now, it seems safe to assume that the human impacts increase with the number of humans visiting the site. Thus, $y$ may be replaced by the increasing function $Y(m)$, where $m$ is the number of visitors. So, adopting this impact function, the evolution of the natural features on the tourist spot is:

$$
\dot{x}=G(x)-Y(m)
$$

In what follows, we will assume that the natural renewal function, $G(x)$ is positive from some positive $x$, declining at least for $x$ beyond a certain level and concave. The impact function is assumed to be at least weakly convex, i.e. the impact may increase faster than proportionately with the number of

2 In this paper vectors will be indicated by bold typescript.

3 A positive impact would be represented by a negative $y$. 
visitors. Thus, the renewal process as a whole is a concave function. Naturally, we take it that $G(0)=Y(0)=0$.

Given (3), an equilibrium of the natural features of the tourist site can only be attained if the number of visitors is constant. Let $m^{\circ}$ represent such a constant. In that case the equilibrium is defined by:

$$
G(x)-Y\left(m^{\circ}\right)=0
$$

It is easy to verify that a higher number of visitors has a negative impact on the equilibrium $x$ provided this equilibrium is stable, i.e. $G_{x<0 .}$.

\subsection{Tourists' demand for access}

Consider a typical tourist faced with the decision about whether to visit a particular tourist site or not. His decision, which may be referred to as $e$, may be modelled as a binary choice variable with $e=0$ denoting not visiting and $e=1$ visiting.

Let the tourist's preferences be represented by the utility function:

$$
U(e \cdot F(x, m), z)
$$

The function $F(x, m)$ represents the quality of the visit with $x$ denoting the natural features of the site and $m$ the number of other visitors there. We assume that the quality function is increasing in $x$ and declining in $m$ and concave. The vector $z$ denotes the consumption of other goods. Obviously if the tourist decides to visit, $e=1$ and his utility is $U(F(x, m), \boldsymbol{z})$. Otherwise his utility is simply $U(0, \boldsymbol{z})$.

In accordance with standard economic theory, we assume that this utility function is increasing and concave in both arguments. It then follows that it is concave in all arguments because an increasing concave function of a concave function, i.e. $F(x, m)$ in this case, is concave.

The tourist's expenditures are constrained by his budget constraint. Let us write this constraint as:

$$
\dot{a}=u-s \cdot e-\boldsymbol{p} \cdot \boldsymbol{z}
$$

where $a$ denotes the tourist's assets, $u$ his exogenous income, $s$ the price of entry to the tourist spot and $p$ the price vector of other goods. As before, $\dot{a}$ denotes the first time derivative of the variable $a$. Note that the price of entry, $s$, may be zero or even negative (as pointed out by an anonymous referee).

It is reasonable to believe that a tourist contemplating whether to visit a particular tourist spot in Iceland takes the quality of the visit, i.e. the function $F(x, m)$ as exogenous. In that case, his decision problem over a short period of time, e.g. a day, may be described as follows: 


$$
\begin{aligned}
\operatorname{Max}_{z, e} & \int_{0}^{t_{1}} U(e \cdot F(x, m), z) \cdot e^{-r \cdot(t)} d t+F\left(a\left(t_{1}\right)\right) \cdot e^{-r \cdot t_{1}} \\
\text { s.t. } \quad & \dot{a}=u-s \cdot e-\boldsymbol{p} \cdot \boldsymbol{z}, \\
& e=\{0,1\},
\end{aligned}
$$

where the curly brackets indicate the opportunity set of the control variable $e$. The function is the terminal value of the maximization depending on the remaining assets at the terminal time $a\left(t_{1}\right)$

The period $\left[t_{0}, t_{1}\right]$ denotes the duration of the visit. If this is finite, the access ticket must be regarded as state a variable the purchase of which represents an investment. To avoid the resulting complexities, which add nothing to the understanding of the economic issues of interest in this paper, it is henceforth assumed that the period $\left[0, t_{1}\right]$ is infinitely short.

Under these assumptions, the necessary conditions for solving problem (I) include the following rules: ${ }^{4}$

$$
\begin{aligned}
& U(F(x, m), z)-U(0, z) \leq \lambda \cdot s \Rightarrow e=0 \\
& U(F(x, m), z)-U(0, z)>\lambda \cdot s \Rightarrow e=1
\end{aligned}
$$

These conditions are readily explainable. The first term on the left-hand-side of the inequalities, represents utility if a visit is undertaken. The second term on the left-hand-side is utility if visit is not undertaken. So the entire left hand side represents the gain in utility (or marginal utility) from a visit. On the right hand side, the (dynamic) Lagrange multiplier $\lambda$ is the tourist's shadow value of his assets, $a$, and $s$ the price of entry. Thus, $\lambda \times s$ represents the marginal cost of a visit measured in terms of the tourist's utility. Given this, the first necessary condition simply says that if additional utility of a visit is less or equal to the utility cost of access, the visit will not take place. The second necessary condition, covers the other case, namely if the additional utility of a visit exceeds the utility cost of a visit, a visit will take place.

Combining the necessary conditions (I.a) and (I.b) with the other necessary conditions for solving problem (I), defines the tourists demand function for visits. This function may be written as:

$$
e=E(s ; x, m, a)
$$

Due to the discrete nature of the decision to visit, this function is a step function as illustrated in figure 2 . For any entry price above the critical one, $s^{*}$, there will not be a visit. However, if the entry price is $s^{*}$ or lower a visit will take place.

4 While these necessary conditions are really quite obvious, they may be formally derived by maximizing the appropriate Lagrangian (or Hamiltonian) function for problem (I). 


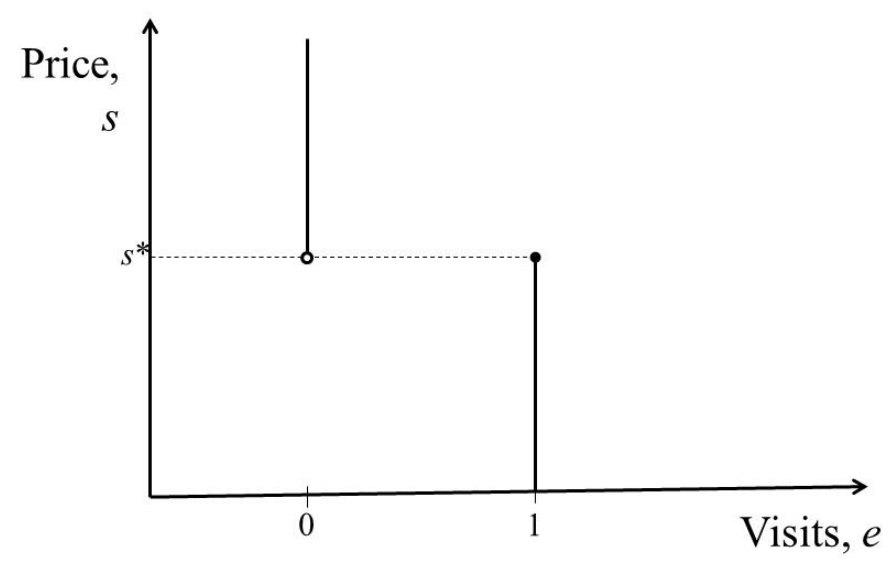

Figure 2. The demand function for visits

Variations in the other independent variables of the demand function will alter the critical price, $s^{*}$. A higher degree of natural features, $x$, and higher level of assets, $a$ will generally increase $s^{*}$ implying that a visit will take place at a higher entry price. On the other hand, more crowding at the tourist spot, i.e. a higher $m$, will reduce $s^{*}$ meaning that the entry price now has to be lower for the tourist to elect to visit.

The demand function, (6), holds for one tourist. Different tourists will generally have different critical prices. Therefore, as is easy to verify, the aggregate demand function for a number of tourists will be more conventional-looking. It will still be a step function but the steps will be more numerous (one step for each tourist) and therefore smaller relative to the total demand. The greater the number of tourists over which the aggregation is carried, the more smooth will the aggregate demand function become. ${ }^{5}$

For later reference it is convenient to write the aggregate demand function as

$$
m=M(s ; x, A)
$$

where $A$ now denotes the total or average assets of the tourists over which the aggregation holds. Note that the crowding effect, via the function $F(x, m)$, is implicit in the form of this function. Basically it simply reduces the demand compared to what would otherwise be the case. Needless to say, this aggregate demand function is falling in $s$ and increasing in the other variables. For a large number of tourists, this function may be taken to be approximately continuous and smooth.

5 This is further explained in appendix 1. 


\subsection{Optimal pricing}

A benevolent social planner seeks to set the number of visits at each point of time so as to maximize the present value of the flow of total utility from the site over time. Thus, for the social planner the time horizon is much longer than for the individual tourist and unlike him he must take account of the impact of each visit on (a) the natural quality of the spot and (b) the degree of crowding at the site.

As before, we consider a given site. Denote the number of potential visitors to the site by $I$. Obviously I can be a very large number. Each potential visitor, $i$, can stay away, $e(i)=0$, or visit $e(i)=1$. The total number of visitors at each point of time, therefore, is $\sum_{i=1}^{I} e(i)$. For each potential visitor the degree of crowding is the number of other visitors at the site which may be denoted by $m(i) \equiv \sum_{j \neq i} e(j)$. Note that there is one $m(i)$ for each visitor. In general there will be certain costs at the site associated with each visit. These costs, among other things, reflect resources spent on admission and to maintain trails, platforms, safety equipment and other facilities. In aggregate these costs may be represented by cost function $C\left(\sum_{i=1}^{L} e(i)\right)$.

Given these specifications, the social planner's problem may be expressed as:

$$
\begin{aligned}
& \underset{\text { all } e(i)}{\operatorname{Max}} V(0)=\int_{0}^{\infty} \sum_{i=1}^{I} U(e(i) \cdot F(x, m(i)), z(i) ; i) \cdot e^{-r \cdot t} d t \\
& \text { s.t. } \sum_{i=1}^{I} \dot{a} \equiv \dot{A}=\sum_{i=1}^{I} u(i)-\boldsymbol{p} \cdot \sum_{i=1}^{I} \boldsymbol{z}(i)-C\left(\sum_{i=1}^{I} e(i)\right) \text {, } \\
& \dot{x}=G(x)-Y\left(\sum_{i=1}^{I} e(i)\right), \\
& m(i)=\sum_{j \neq i} e(j), \text { all } i, \\
& e(i)=\{0,1\} \text {, all } i \text {. }
\end{aligned}
$$

The first two constraints in (II) are dynamic in the sense that they involve the evolution of the state variables, the assets $A$ and the natural features $x$, respectively. Note that in the aggregate budget constraint (the first constraint in (II)) the access prices paid by visitors cancel out because it exactly equals 
the revenue from visits. The third constraint, which is really a set of $I$ constraints, defines the degree of crowding at the site as seen by each potential visitor. While this set of constraints could easily be substituted out, it is convenient to include it explicitly to highlight the social cost of crowding.

The sum of individual utilities in the integrand in (II) may of course be regarded as a particular social welfare function often referred to as classical utilitarianism (Bentham 1789, Mill 1863, Dasgupta 1995). The fundamental assumption of classical utilitarianism is that the utility functions exist and the social planner knows them. An important implication is that all individual are treated equally so classical utilitarianism is inherently egalitarian (Sen 1970, 1973).

To clarify the optimal pricing rule to be expressed below, it may be helpful to write a Hamiltonian (dynamic Lagrangian) function for problem (II) as:

$$
\begin{aligned}
H=\sum_{i=1}^{I} U(e(i) \cdot F(x, m(i)), z(i) ; i)+\lambda \cdot\left(\sum_{i=1}^{I} u(i)-\right. & \boldsymbol{p} \cdot \sum_{i=1}^{I} z(i)-C\left(\sum_{i=1}^{I} e(i)\right)+\sigma \cdot\left(G(x)-Y\left(\sum_{i=1}^{I} e(i)\right)\right) \\
& +\sum_{i=1}^{I} \mu(i) \cdot\left(m(i)-\sum_{j \neq i} e(j)\right)+\sum_{i=1}^{I} \eta(i) \cdot(1-e(i)) .
\end{aligned}
$$

In this formulation, $\lambda$ is the shadow value of the aggregate budget constraint defined by $\lambda(t)=\partial V(t) / \partial x(t)$, where $V(t)$ is the maximum utility value obtainable from the site. $\sigma$ is the shadow value of natural features defined by $\sigma(t)=\partial V(t) / \partial x(t)$. The $\mu(i)$ s formally represent the shadow value of relaxing the constraint $m(i)=\sum_{j \neq i} e(j)$. So, the $\mu(i)$ s are really the shadow values of less crowding to each visitor. Finally, the $\eta(i)$ s measure the shadow value of being allowed more than one visit.

It is now straight-forward to verify that the optimal entry rule for a potential visitor $i$ is: ${ }^{6}$

$$
\begin{aligned}
& U(F(x, m), z ; i)-U(0, z ; i) \leq \sigma \cdot \Delta Y(i)+\sum_{j \neq i} \mu(j)+\lambda \cdot \Delta C(i) \Rightarrow e(i)=0 \\
& U(F(x, m), z ; i)-U(0, z ; i)>\sigma \cdot \Delta Y(i)+\sum_{j \neq i} \mu(j)+\lambda \cdot \Delta C(i) \Rightarrow e(i)=1
\end{aligned}
$$

where $\Delta Y(i)$ and $\Delta Y(i)$ are shorthand notations for $Y\left(\sum_{i=1}^{I} e(i)\right)-Y\left(\sum_{j \neq i} e(j)\right)$ and $C\left(\sum_{i=1}^{I} e(i)\right)-C\left(\sum_{j \neq i} e(j)\right)$, respectively.

6 According to Pontryagin's maximum principle (Pontryagon et al. 1962), the control variables, $e(i)$ all $i$, should maximize the Hamiltonin equation at all times. 
Needless to say, conditions (II.a) and (II.b) hold for all potential visitors, $i=1,2 \ldots$. I. According to these conditions, it is likely that some of them should visit the site while others should not. Those that should visit are those who gain more utility from it, generate less costs, cause less environmental damage and less crowding.

Comparing this socially optimal visiting rule with the tourists' private one, (I.a) and (I.b) in section 2.1, reveals:

- The tourists' private decision rule is in general inappropriate. It is inappropriate because it ignores the natural feature externality (expressed by $\sigma \cdot \Delta Y(i)$ ), the crowding externality (expressed by $\sum_{j \neq i} \mu(j)$ ), and the direct costs caused by each visit (expressed by $\lambda \cdot \Delta C(i)$ ).

- The tourists' private decision rule however will be appropriate if their utility value of the entry fee, $s$, equals these costs, i.e. $\lambda(i) \cdot s=\sigma \cdot \Delta Y(i)+\sum_{j \neq i} \mu(j)-\lambda \cdot \Delta C(i)$ for all $i$.

it immediately follows that the optimal entry pricing rule is:

$$
s^{*}(i)=\frac{\left(\sigma \cdot \Delta Y(i)+\sum_{j \neq i} \mu(j)-\lambda \cdot \Delta C(i)\right)}{\lambda(i)}, \text { all } i
$$

According to the optimal pricing rule expressed in (8), the entry price should vary across visitors. This is because it is derived by maximizing the sum of utilities across all the potential visitors. As a result individual marginal utility of funds, $\lambda(i)$, affects the optimal pricing. Those with a higher marginal utility of funds (because they have less funds or for other reasons) should be charged less than the others. In this way, the enjoyment of scarce tourist sites is allocated across the potential tourists so as to maximize the flow of total utilities from these sites.

Other reasons why the optimal entry price in (8) differs across potential tourists are that they may have (i) differential negative effects on the natural features of the site measured by $\Delta Y(i)$, (ii) lead to more crowing disutility measured by $\sum \mu(j)$ and (iii) cause more direct costs, $\Delta C(i)$. 
Assuming, as is common in policy analysis, that all marginal utilities of income are equal, in which case they can be set to unity (equivalent to re-scaling the utility functions), and that all shadow values of less crowding are equal, $\mu(i)=\mu(j)$ for all $i$ and $j$ and normalizing the shadow value of social funds to unity, i.e. $\lambda=1$ (equivalent to rescaling costs), the optimal pricing rule simplifies to:

$$
s^{*}(i)=\sigma \cdot \Delta Y(i)+(m-1) \cdot \mu+\Delta C(i), \text { all } i
$$

Moreover, if all visitors have the same effect on the natural features and direct costs, the optimal pricing rule becomes identical for every visitor:

$$
s^{*}=\sigma \cdot \Delta Y+(m-1) \cdot \mu+\Delta C
$$

The pricing rule expressed in (10) is easy to interpret. The entry price should equal the sum of the environmental costs, the crowding costs (remember $m$ is to total number of visitors) and the direct costs caused by each visit. Of course, if visits generate other externalities not accounted for in the above, those should be included in the price as well.

Pricing rule (10) although relatively simple is not easy to apply perfectly. To calculate $s^{*}$ requires knowledge of the shadow values of natural features, $\sigma$, and less crowding, $\mu$, as well as the marginal impact of visitors on the natural features, $\Delta Y$, and costs, $\Delta C$. To work out $\sigma$, and crowding, $\mu$, requires knowledge of all the components of the maximization problem (II) including the utility functions of potential visitors. Obviously, these problems apply even more so to the more complicated pricing rules (8) and (9). Therefore, in practice, optimal pricing rules can only be approximated.

\subsection{Profit maximization}

The great majority of the visitors to tourist sites in Iceland are foreign (see e.g. Geirsson og Jóhannesdottir 2013 and Jónsdóttir 2016). Therefore, instead of maximizing their utility, a more natural objective for Icelandic society and, of course site owners is to set access price so as to maximize the flow of net revenues or profits from the sites.

As explained in section 2.1, the aggregate demand function for visits to a particular site may be written as:

7 Since some of the site visitors are Icelanders it would be even more in line with the national interest to maximize the total benefits to Iceland defined as net revenues from foreign tourists plus a monetary measure of the utility benefits gained by Icelanders visiting the sites. This, however, is a significantly more complicated exercise which cannot be accommodated within the confines of the current paper. 


$$
m=M(s, x),
$$

where we have dropped explicit reference to the exogenous total assets, A. In section 2.1 and appendix 1, it is argued that for a significant number of potential visitors, this function may be taken to be approximately smooth in s. In what follows we will adopt this assumption. Note also that unless the derivative $\mathrm{Ms}=0$ this demand function gives the maximizer (the site owner) a degree of monopoly power. ${ }^{8}$

The maximization problem may now be written as:

$$
\begin{gathered}
\operatorname{Max}_{s} \int_{0}^{\infty}\left(s \cdot M(s, x)-C(M(s, x)) \cdot e^{-r \cdot t} d t\right. \\
\text { s.t. } \dot{x}=G(x)-Y(M(x, s)) .
\end{gathered}
$$

A necessary condition for solving this problem is the pricing rule:

$$
M(s, x)+s \cdot M_{s}-C_{m} \cdot M_{s}-\lambda \cdot Y_{m} \cdot M_{s}=0
$$

provided that a positive number of visits is optimal. This necessary condition can be reduced to the more concise form:

$$
s^{\circ}=\left(C_{m}+\lambda \cdot Y_{m}\right) \cdot\left(\frac{E(m, s)}{1+E(m, s)}\right)
$$

where $s^{\circ}$ is the net revenue maximizing entry price and $E(m, s)$ is the elasticity of demand with respect to the entry price. Since this is negative and less than unity ${ }^{9}$, the last term of $\mathrm{s}^{\circ}$, i.e., $\left(\frac{E(m, s)}{1+E(m, s)}\right)$, must be greater than one.

It is not easy to compare the pricing rule (11) with the overall optimal one given by (10) let alone its more involved versions, (8) and (9) in section 2.2. However, the overall optimal pricing rule of section 2.2 may be approximated by maximizing the sum of consumers' and producer's surpluses from the site. This, as demonstrated in appendix 2, generates the pricing rule:

$$
M(s, x)-C_{m} \cdot M_{s}-\lambda \cdot Y_{m} \cdot M_{s}=0
$$

8 Since each site is unique, this may be regarded as a case of natural monopoly (see e.g. Mill 1848, book IV chapter 2, Varian 1987). This, however, does not imply that there may not be imperfect substitutes for any given site. If there are, which is likely, the optimal pricing issue, whcih now hast o take account of pricing responses at other sites, becomes considerably more complicated.

9 Note that $\mathrm{E}(\mathrm{m}, \mathrm{s})<-1$ for $\mathrm{s}^{\circ}$ to be a possible solution to problem (III). 
So, compared to pricing rule that maximizes net revenues from the site, i.e., (11), rule (12) drops the term $s \cdot M s$. Since this term is non-positive it is readily seen that maximizing net revenues from the site reduces the number of visitors compared to maximizing total benefits and, therefore, also implies higher access price.

To apply the net revenue maximizing rule (11) requires knowledge of the site demand function, $M(s, x)$, the natural features impact function, $Y(m)$ and the cost function of visits, $C(m)$ as well as the shadow value of the natural features, $\sigma$. Since the demand function is in principle estimable from market data, applying (11) or, for that matter (12), appears more feasible that to apply the pricing rules (8) to (10).

\section{Conclusions}

Tourist sites in Iceland, as well as around the world, are subject to scarcity for at least two reasons; (i) their natural features are negatively affected by visits (reducible resources) and (ii) the enjoyment of visits is negatively affected by the number of other visitors (crowding). The analysis of this paper shows that that, under these conditions, it is socially beneficial to restrict access by charging a positive access fee. If, in addition, visitors generate direct outlays, e.g. in terms of maintenance of site infrastructure and facilities, these should also be covered by the access fee.

A simplified version of the socially optimal access fee derived in sections 2.2 is:

$$
s^{*}=C_{m}+\sigma \cdot Y_{m}+(m-1) \cdot \mu
$$

where $m$ denotes the number of visits, $C_{m}$, the marginal cost of each visit, $Y_{m}$ the marginal damage of visits to the site, $\sigma$ the shadow value of damage and $\mu$ the shadow value of crowding at the site. More detailed versions of the same basic access pricing rule are derived in section 2.2.

Equation (13) expresses the basic principles of optimal pricing of access to a given tourist site. The access price should cover the direct outlays, the damage to the natural features of the site and the crowding effect of marginal visits. Needless to say, if further dimensions of scarcity associated with visits to the site, further terms to cover these need to be added to the pricing rule.

The optimal access price defined by equation (13) or its more advanced variants is not some number but a function. This function, and therefore the price, depends inter alia on the preferences (utility functions) of the potential visitors, their income and other consumption alternatives. It also depends on the number of visitors at each point of time and many other variables. Thus, generally the optimal access price may be expected to increase with the in- 
terest in the sites, income levels and the number of visitors. Moreover, even when these exogenous variables are constant, the optimal price will evolve time (usually increase) as the natural features of the site converge to their long term optimal equilibrium which will prevail in that case.

By the same token, the optimal access price will generally differ across sites. It will be highest for sites in high demand that are also sensitive to damage of their natural features and crowding and lower for the others. Thus, it is entirely conceivable that there are sites for which the optimal access price is zero.

It is crucial to appreciate that rule (13) and its more advanced variants represent the socially optimal price, i.e., the price that maximizes the present value of the flow of utilities from visiting the site. It immediately follows that free access, far from being a social virtue, is actually socially detrimental in many cases. It often leads to an excessive number of visits with the resulting excessive deterioration of natural features of the site and crowding which will reduce the present value of utilities obtainable from the site. Only in the cases where the optimal price is actually zero would free access actually be socially optimal.

The pricing rule expressed by equation (13) and its more advanced variants maximizes the present value of utilities flowing from the site. It has nothing to do with generating profits from the sites or even paying for the costs associated with entry. However, since parts of the pricing rule are charges for the impact on the natural features of the site and crowding it is likely, although not certain, the entry fee revenues will be more than sufficient to pay for the direct outlays associated with visits to the site.

If the objective is to maximize net revenues from tourist sites - a reasonable objective for the owners of the sites and even the Icelandic government, the pricing rule is:

$$
s^{\circ}=\left(C_{m}+\lambda \cdot Y_{m}\right) \cdot\left(\frac{E(m, s)}{1+E(m, s)}\right)
$$

where $E(m, s)$ is the elasticity of visits with respect to the access price. It can be shown that provided the entry price has an impact on visits, the entry price that maximizes the net revenues from the tourist sites exceeds the socially optimal one. Consequently it is also more conservative of the natural features of the sites.

Applying pricing rules (13) or, for that matter, (14) is not easy. To apply the optimal one, (13), or its more advanced variants requires knowledge of all the ingredients entering the maximization problem (II) including the visitors' utility functions and their impacts on the natural features of the sites as well as the site renewal functions and, of course, the cost function, $C(m)$. To apply equation (14) is slightly more feasible because the individual utility functions 
are reflected in the demand functions which are in principle observable in the market place.

\section{References}

Arrow, K.J. \& Hahn, F.H. (1971). General Competitive Analysis. San Franscisco: Holden-Day. Baumol. W.J. \& Oats, W.E. (1988). The Theory of Environmental Policy 2nd ed. Cambridge UK: Cambridge University Press.

Bentham, J. (1789). An Introduction to the Principles of Morals and Legislation. Republished as Dover Philosophical Classics. UK: Dover Publications.

Clarke, H. \& Ng, Y-K. (1993). Tourism, Economic Welfare and Efficient Pricing. Annals of Tourism Research, 20 (4), 613-32.

Cropper, M.L. \& Oats, W.E. (1992). Environmental Economics: A Survey. Journal of Economic Literature, 30 (2), 675-740.

Dasgupta, P. (1995). An Inquiry into Well-being and Destitution. Oxford: Clarendon Press.

Farzin, Y. (1996). Optimal Pricing of Environmental and Natural Resource Use with Stock Externalities. Journal of Public Economics 62 (1-2), 31-57.

Ferðamálastofa (2017). http://www.ferdamalastofa.is.

Hanley, N., Shogren, J.F. \& White, B. (1997). Environmental Economics in Theory \& Practice. Macmillan Text in Economics. UK: Macmillan Press.

Geirsson, Á. \& Jóhannesdóttir,K. (2013). Fjármögnun Uppbyggingar og Viðhalds Ferðamannastaða. Reykjavik: Icelandic Tourist Board.

Jónsdóttir, E.R. (2016). Í ólgusjó Deilna og Ólíkra Sjónarmiða. B.Sc. dissertation. Reykjavik: University of Reykjavik.

Laarman, J. \& Gregersen, H. (1996). Pricing Policy in Nature-based Tourism. Tourism Management, 17 (4), 247-54.

Landeigendafélags Geysis (2015). Ályktun Stjórnar 20.3.2015. Morgunblaðið 12.32015.

Lindberg, K. (1991). Policies for Maximizing Nature Tourism's Ecological and Economic Benefits. Washington, DC: World Resources Institute.

Mill, J.S. (1848). Principles of Political Economy with Some of their Applications to Social Philosophy. London: John W. Parker.

Mill, J.S. (1863). Utilitarianism. (R. Crisp editor). Oxford: Oxford University Press.

Pigou, A.C. (1920). Economics of Welfare. London: Macmillan Press.

Pontryagin, L.S, Boltyanski, V.S., Gramkeldize R.V. \& Mishchenko, E.F. (1962). The Mathematical Theory of Optimal Processes. New York: Wiley.

Richer J. \& Christensen, N. (1999). Appropriate Fees for Wilderness Day Use: Pricing decisions for Recreation on Public Land. Journal of Leisure Research, 31 (3), 269-80

Sen A. (1970). Collective Choice and Social Welfare. San Francisco: Holden-Day.

Sen, A. (1973). On Economic Inequality. Oxford: Claredon Press.

Spence, M. \& Weitzman, M.L. (1978). Regulatory Strategies for Pollution Control. In A. Friedlander (ed.) Approaches to Controlling Air Pollution. Cambridge MA: MIT Press.

Tietenberg. T.IL. 1990. Economic Instruments for Environmental Regulation. Oxford Review of Economic Policy 6 (1), 17-33.

Varian, H. (1987). Intermediate Microeconomics: A Modern Approach. New York: Norton \& Company.

Viðskiptablaðið (2015). http://www.vb.is/frettir/saka-stjornvold-um-seinagang-og-ahugaleysi/115449/?q=Geysi. 


\section{Appendix 1}

\section{The aggregate demand function}

Tourist's $i$ demand for a visit to a given place is a single step function of the access price which may be expressed as:

$$
e(i)=E(s(i) ; i), e(i)=0,1,
$$

with the step occurring at a certain critical price $s^{*}(i)$, say. The graph of this function is illustrated in figure 2 in the main text.

With I non-identical tourists the number of critical prices may be as high as $I$. It follows that the number of steps in the aggregate demand function will be equally numerous. Now the length of the step between prices may be regarded as an inverse measure of the smoothness of the aggregate demand function - the shorter this length the more smooth the function. For more concreteness, let the highest critical price be smax and the lowest zero. Thus the average length of price steps is smax/I. It immediately follows that the average step length will be shorter and therefore the aggregate demand for visits smoother as the number of potential visitors increases. Figure A.1 attempts to illustrate this for six potential visitors. Obviously, the demand curve depicted is more smooth than the one for just one or two potential customers.

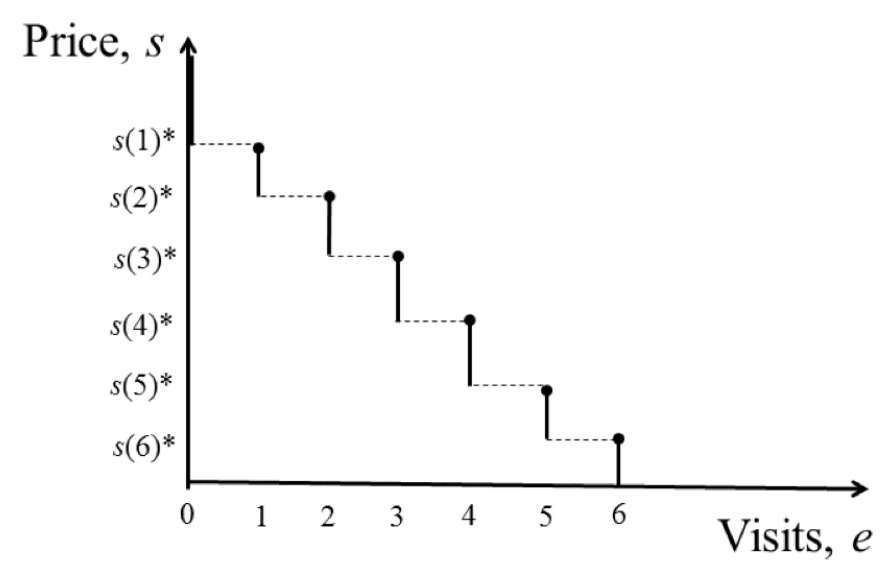

Figure A.1. The aggregate demand of six potential visitors

On the basis of these arguments, it should now be clear that the smoothness of the aggregate demand function increases with the number of potential visitors and in the limit where the number of potential visitors goes to infinity, aggregate demand will converge to a completely smooth function of access price. 


\section{Appendix 2 \\ Maximizing total surplus}

Total net surplus from a site is defined as:

$$
S(s)=\int_{0}^{s} M(\hat{s}, x) d \hat{s}-C(M(s, x)),
$$

where the first term on the left-hand side is gross surplus and the second the cost of receiving $M(s, x)$ visitors.

Maximizing the total net surplus from the site requires solving the problem:

$$
\begin{gathered}
\operatorname{Max}_{s} \int_{0}^{\infty}\left(\int_{0}^{s} M(\hat{s}, x) d \hat{s}-C(M(s, x))\right) \cdot e^{-r \cdot t} d t \\
\text { s.t. } \quad \dot{x}=G(x)-Y(M(x, s)) .
\end{gathered}
$$

A necessary condition for solving this problem is:

$$
M(s, x)-C_{m} \cdot M_{s}-\lambda \cdot Y_{m} \cdot M_{s}=0,
$$

where $\lambda$ is the shadow value of the natural features of the site. 